\title{
Review
}

\section{Apoptosis and necrosis: Intracellular ATP level as a determinant for cell death modes}

\author{
Yoshihide Tsujimoto \\ 1 Osaka University Medical School, Biomedical Research Center, Suita, Osaka \\ 565, Japan; tel: 06-879-3360; fax: 06-879-3369; \\ e-mail: tsujimot@gene.med.osaka-u.ac.jp
}

Received: 5.3.97; revised: 7.4.97; accepted: 10.4 .97

Edited by P. Nicotera

\begin{abstract}
Apoptosis and necrosis are two distinct modes of cell death with respective morphological characteristics. However, apoptosis and some forms of necrosis must share common steps since both modes of cell death can be suppressed by the anti-apoptotic Bcl-2 protein and caspase inhibitors. IntracelIular ATP levels have been implicated both in vitro and in vivo as a determinant of the cell's decision to die by apoptosis or necrosis.
\end{abstract}

Keywords: ATP, necrosis, apoptosis, mitochondria, bcl-2, caspase

Abbreviations: $\mathrm{PI}$ : propidium iodide ICE: interleukin-1Bconverting enzyme

\section{General considerations of cell death - apoptosis versus necrosis}

Apoptosis, a mechanism of cell death, plays an important role in a variety of biological events, including morphogenesis, homeostatic maintenance of various tissues and removal of harmful cells (reviewed by Steller, 1995). Thus, dysregulated cell death can clearly lead to a variety of diseases (reviewed by Thompson, 1995). Apoptosis is characterized by chromatin condensation, nuclear fragmentation and formation of apoptotic bodies, which are phagocytosed by other cells (Wyllie et al, 1980). Apoptosis is tightly regulated by molecular mechanisms that appear to be evolutionary conserved (reviewed by Steller, 1995), and is therefore thought to be an active process in removing unnecessary cells. In most but not all forms of apoptosis, nuclear DNA is cleaved at internucleosomal sites. By contrast, cellular necrosis is defined by electron-lucent cytoplasm, mitochondrial swelling, loss of plasma membrane integrity without drastic morphological changes in nuclei. Necrosis has been considered a passive degenerative phenomenon induced by direct toxic or physical injuries, which most often occurs accidentally (Hawkins et al, 1972; Alison and Sarraf, 1994). Nuclear DNA is randomly cleaved as a consequence of cellular degeneration. Leakage of the cytoplasm through plasma membrane disruption induces cellular inflammatory responses. However, even at pathological regions or when cells are subjected to pathological reagents, apoptotic cells are often observed, indicating that accidental cell death can also proceed by apoptosis. Furthermore, dying cells with nonapoptotic morphological characteristics are observed during naturally occurring cell death. Thus, several forms of cell death which are currently defined by their morphology or by natural or accidental occurrence will soon be categorized according to their molecular mechanism.

\section{Definitive assessment of apoptosis and necrosis}

Because of the morphological definition of apoptosis, the best way to assess modes of cell death, apoptosis or necrosis is electron microscopy. However, it is not a very convenient way to determine the relative frequency of dead cells with apoptotic or necrotic features especially when dead cells in each mode simultaneously appear, for instance, when cells are subjected to hypoxia (Shimizu et al, 1995, 1996a). One of the convenient ways is to use fluorescence microscopy in conjunction with different cell staining (Shimizu et al, 1996a). Cells can be doublestained by calcein-AM (green) which stains whole cells except vacuole, associated with necrosis, irrespective of membrane integrity, and propidium iodide $(\mathrm{PI})($ pink) which stains only nuclei in cells which disrupted plasma membrane integrity, a hallmark of necrosis. The stained cells are visualized under a confocal microscope. Alternatively, cells can be stained by PI (red) and Hoechest 33342 (blue). Hoechst 33342 dye stains nuclei of all cells whereas $\mathrm{Pl}$ stains only cells with disrupted membrane integrity and visualized under a nonconfocal fluorescence microscope. How apoptotic and necrotic cells look by respective staining procedure are summarized in Table 1 and the representative photographs shown in Figure 1.

\section{The common machinery of apoptosis}

Apoptosis can be induced by a variety of stimuli, including depletion of growth factors, hormones, heat shock, $\gamma$ irradiation and crosslinking of Fas antigen (reviewed by Thomspon, 1995). Apoptotic signal transduction pathways activated by various treatments converge into a common pathway, which is driven by ICE/Ced-3 family protease, designated caspases (reviewed by Martin and Green, 1995; Alnemri et al, 1996), and negatively regulated by anti-cell death proteins such as the Bcl-2/Ced-9 family (reviewed by Cory, 1995) and the IAP family (Clem and Miller, 1994; Hay et al, 1995). However, the biochemical basis of the functions of these anti-apoptotic proteins remains unknown.

A number of mammalian ice-related genes have been identified, and ICE (caspase-1)(-like), Ich-1 (caspase-2) 
(-like), and CPP32/Yama (caspase-3)(-like) proteases have been implicated in apoptosis, primarily based on inhibition of apoptosis by their synthetic or natural inhibitors (reviewed by Kumar, 1995). Caspases are initially produced as inactive precursors (zymogens) which are subjected to specific proteolytic cleavage for their activation. Caspases have been suggested to constitute a protease cascade, based on observations that they cleave other members of the family in vitro to activate them (reviewed by Martin and Green, 1995). Recently, sequential activation of caspase 1(-like) and caspase 3(-like) proteases has been shown to be required for apoptosis in vivo, which is induced by different stimuli including Fas stimulation, VP16 and calcium ionophore (Enari et al, 1996; Shimizu et al, 1996c). Although several

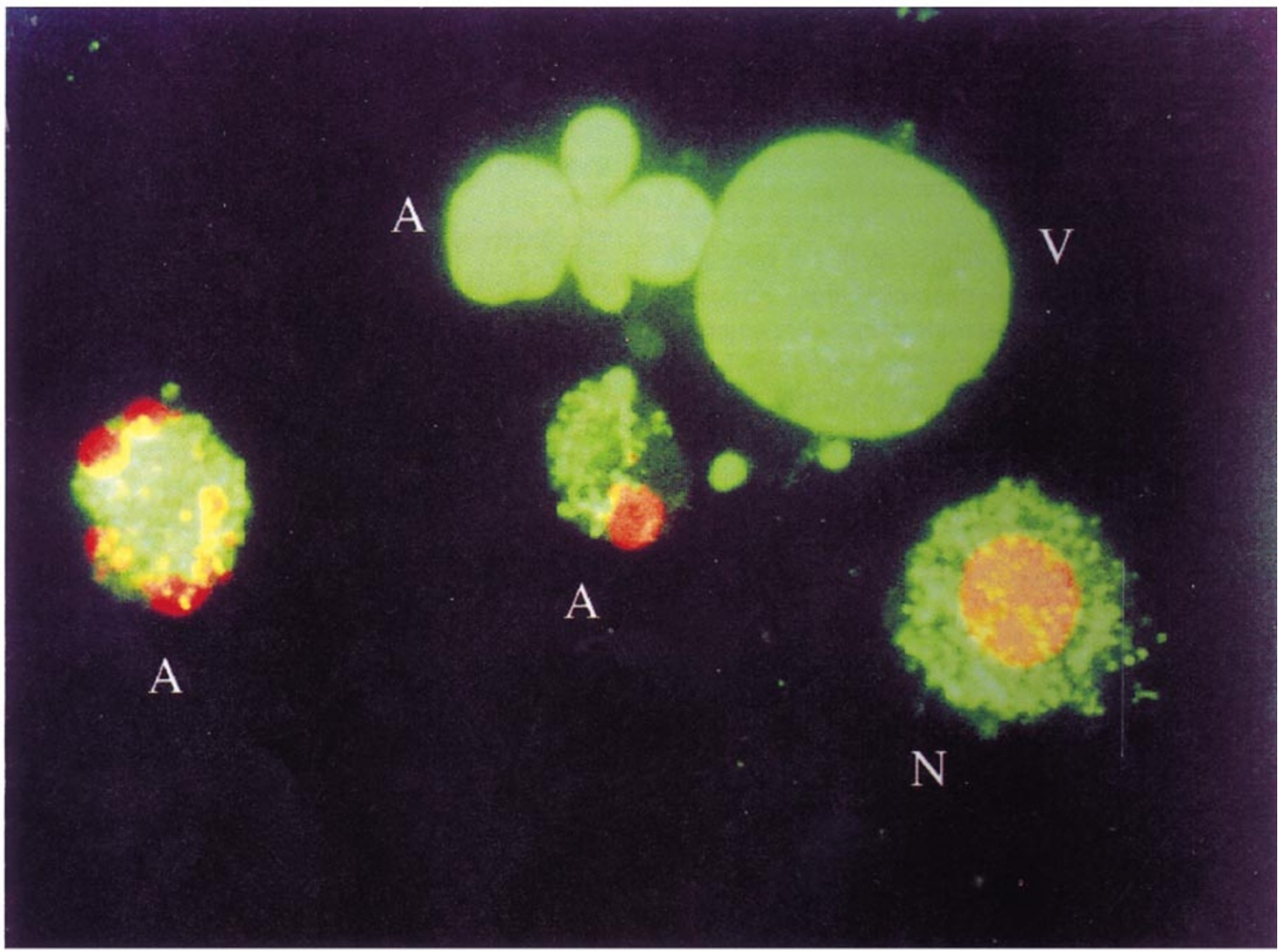

b

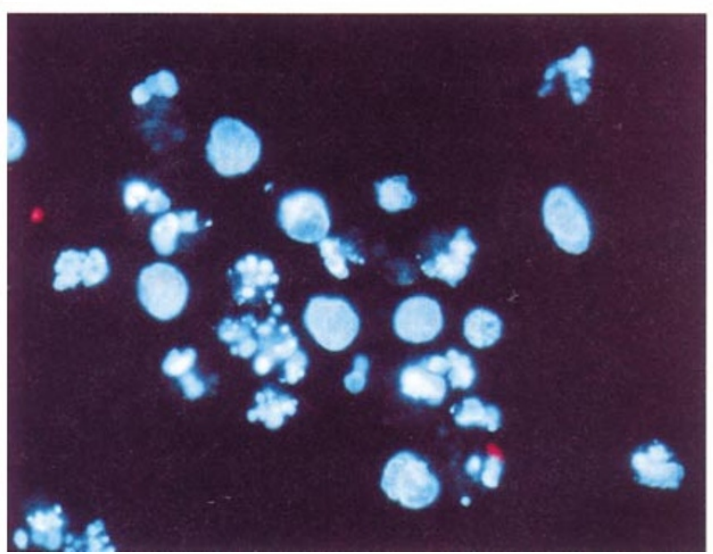

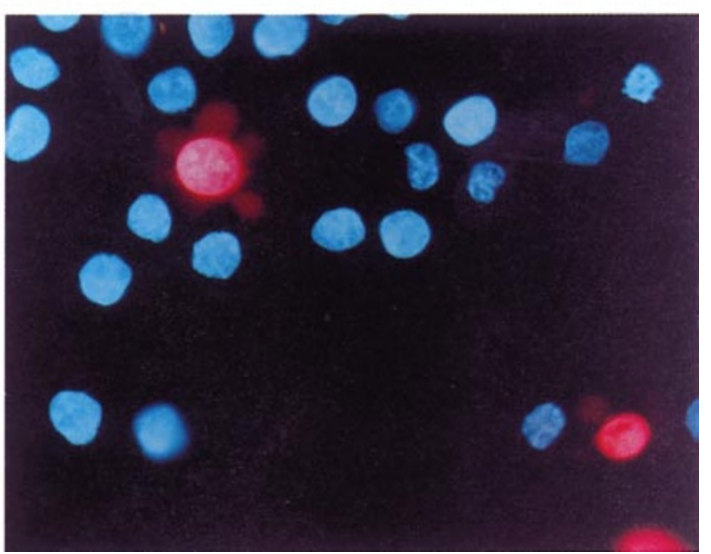

Figure 1 Assessment of apoptosis and necrosis using fluorescence microscopy (a) confocal fluorescence micrograph of PC12 cells treated with hypoxia after being stained with calcein-AM and PI (modified from Shimizu et al, 1996a). A, N and V indicate apoptotic, necrotic and viable cell, respectively. (b,c) nonoconfocal fluorescence micrographs of apoptotic (b) and necrotic Hela cells (c) stained with PI and Hoechst 33342 
Table 1 Cell death modes assessed by fluorescence staining

\begin{tabular}{|c|c|c|c|c|}
\hline & \multicolumn{2}{|c|}{ Confocal } & \multicolumn{2}{|c|}{ Nonconfocal } \\
\hline & \multirow{3}{*}{\multicolumn{2}{|c|}{$\begin{array}{c}\text { Calcein-AM } \\
\text { (green) }\end{array}$}} & \multicolumn{2}{|r|}{ Hoechst } \\
\hline & & & PI & 33342 \\
\hline & & & (red) & (blue) \\
\hline & Cell sha & icuole & Nuclei & Nuclei \\
\hline Viable & $\mathrm{R}^{*}$ & - & Not stained & $\mathrm{R}$ \\
\hline Necrosis & $\mathrm{R}$ & + & $\mathrm{R}$ & $\mathrm{R}$ \\
\hline Early apoptosis & $\mathrm{F}^{\star \star}$ & - & Not stained & $\mathrm{F}$ \\
\hline Terminal apoptosis & $\mathrm{F}$ & - & $\mathrm{F}$ & $\mathrm{F}$ \\
\hline
\end{tabular}

*round, **fragmented.

cellular victims for caspases such as poly (ADP-ribose) polymerase, actin and lamins have been described, an essential role for the cleavage of victims in apoptosis has not been directly demonstrated. True targets for caspases remains to be elucidated.

\section{Inhibition of some forms of necrosis by Bcl-2 and caspase inhibitors}

Although $\mathrm{Bcl}-2$ and caspase inhibitors had been thought to specifically inhibit apoptosis, preventive effects of Bcl-2 on necrosis were occasionally observed (Strasser et al, 1991; Kane et al, 1993; Shimizu et al, 1995). More convincing evidence for the role of $\mathrm{Bcl}-2$ in necrosis was provided by the demonstration that $\mathrm{Bcl}-2$ and its relative $\mathrm{Bcl}-\mathrm{x}_{\mathrm{L}}$ inhibit necrotic cell death induced by oxygen depletion (Shimizu et al, 1996a, e), respiratory chain inhibitors such as KCN and antimycin A (Shimizu et al, 1996b) or by glutathione depletion (Kane et al, 1995), as confirmed morphologically by electron microscopy. Such necrotic cell death was also retarted by caspase inhibitors including tetrapeptide inhibitors and a serpin, CrmA derived from cowpox virus (Shimizu et al, 1996b-e). These results indicate that apoptosis and some forms of necrosis share common steps, at least common target sites for $\mathrm{Bcl}-2 /$ $\mathrm{Bcl}-\mathrm{x}_{\mathrm{L}}$ and for caspases (Figure 2).

Anti-apoptotic Bcl-2 localizes in multiple membrane compartments, including the nuclear envelope, endoplasmic reticulum and mitochondrial membranes (Hockenbery et al, 1990; Monaghan et al, 1992; Jacobson et al 1993; Akao et al, 1994). However, the subcellular compartment in which $\mathrm{Bcl}-2$ acts to prevent cell death has not been precisely identified. Accumulating evidence indicates that overexpressed $\mathrm{Bcl}-2$ prevents the activation of caspases in apoptosis and hypoxia-induced necrosis, suggesting that Bcl-2 prevents cell death by acting upstream of the activation of caspases (Chinnaiyuan et al, 1996; Boulakia et al, 1996; Shimizu et al, 1996c; Armstrong et al, 1996). Several models for Bcl-2's ability to block the activation of the caspase cascade have been proposed: (1) Bcl-2 prevents mitochondrial dysfunction such as membrane potential $(\Delta \Psi)$ loss and membrane permeability transition (PT) (Zamzami et al, 1995a; Shimizu et al, 1996d) which allows the release of mitochondrial apoptogenic factors such as cytochrome c (Liu et al, 1996) and AIF (Susin et al, 1996) (discussed by G Kroemer, 1997) (2) Bcl-2 sequesters caspases by interaction through a ced-4-like protein

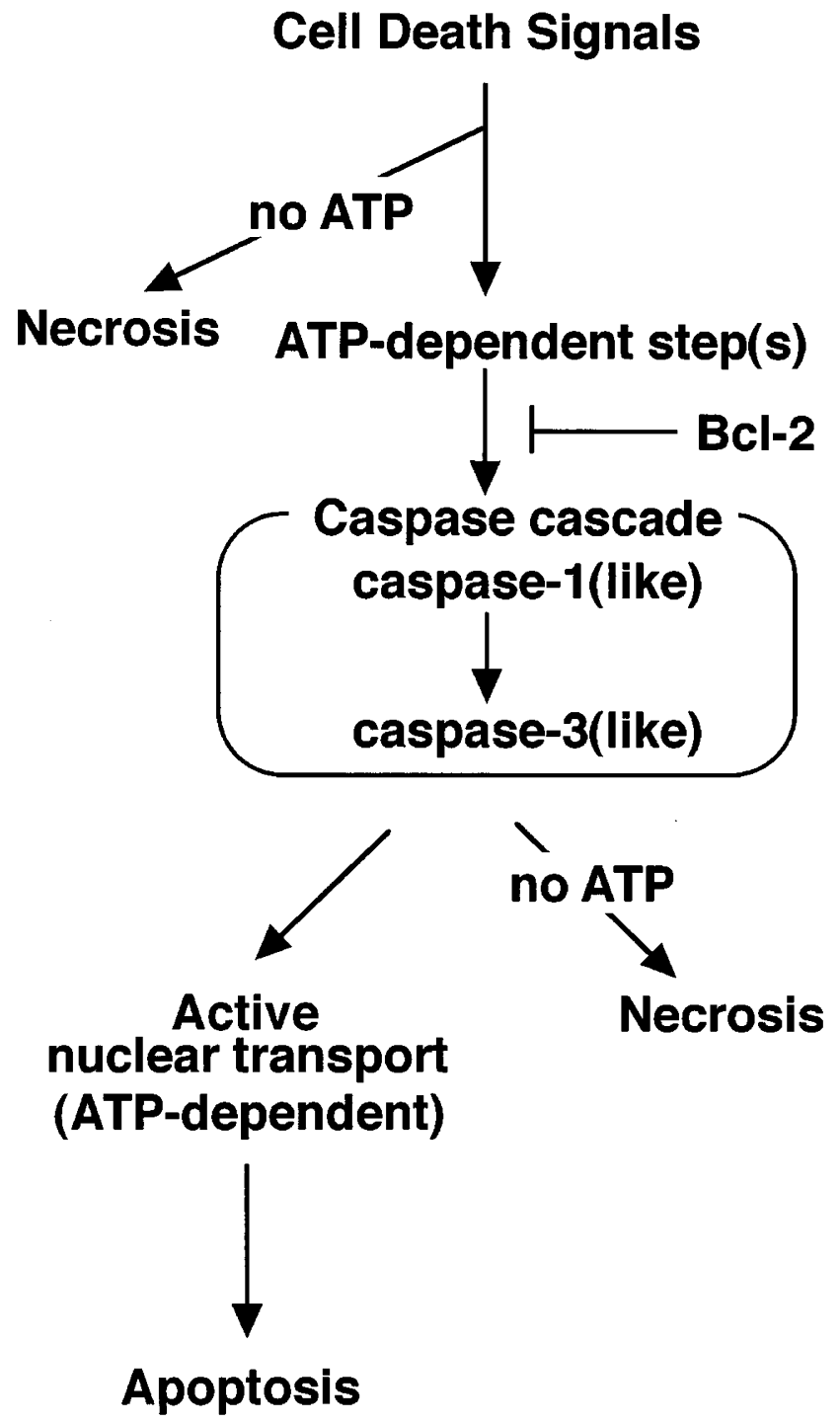

Figure 2 Apoptosis and some forms of necrosis share a common signal transduction pathway

(Chinnaiyan et al, 1997) and (3) Bcl-2 inhibits the $\Delta \Psi$ independent release of cytochrome $c$ which leads to the activation of the caspases (Yang et al, 1997; Kluck et al, 1997).

\section{ATP, an intracellular determinant of cell death by apoptosis versus necrosis}

What might determine whether cells die by apoptosis or necrosis? One evident physiological difference in cells undergoing apoptosis versus necrosis is in the levels of intracellular ATP. Since ATP depletion itself induces necrosis, indicating that necrosis does not require intracellular ATP, studies were done to directly address the question whether apoptosis is ATP-dependent (Eguchi et al, 1997). Depletion of intracellular ATP by incubating cells in glucose-free medium to halt glycolysis, in the presence of the mitochondrial $F_{0} F_{1}$-ATPase inhibitor 
oligomycin, completely blocked apoptosis induced by Fas stimulation, VP16, dexamethasone or calcium ionophore, and ATP supplied through either glycolysis or mitochondrial oxidative phosphorylation restored the apoptotic cell death pathway, indicating that apoptosis is ATP-dependent (Eguchi et al, 1997). The same conclusion was also reached by Leist et al, (1997) (discussed by Nicotera and Leist, 1997).

Shimizu et al, (1995d), measured intracellular ATP levels during cell death, and shown that intracellular ATP levels remain unchanged until the very end of apoptotic process such as disruption of plasma membrane. Since it has been reported that loss of mitochondrial membrane potential which halts mitochondrial ATP production, is an early step in apoptosis (Zamzami et al, 1995b; Shimizu et al, 1996d), intracellular ATP required for the rest of apoptotic processes must be provided from glycolysis.

\section{ATP-dependent steps both upstream and downstream of the activation of executioner caspases}

ATP-dependent steps exist both upstream and downstream of caspase 3(-like) protease activation in the apoptotic signal transduction pathway activated by various apoptotic stimuli (Figure 2). Which step in apoptosis is ATPdependent? Because apoptosis is characterized by morphological changes in the nucleus, the apoptotic death signals must be transmitted from the cytoplasm to the nucleus. It has recently been shown that active nuclear transport, which is responsible for transfer of relatively large molecules across the nuclear membrane through nuclear pores, is essential for Fas-mediated and recombinant active caspase 3-induced apoptosis (Yasuhara et al, 1997), indicating that a cytoplasmic apoptotic effector(s) with a relatively large molecular weight must be transferred to the nucleus in other to induce apoptotic changes in the nucleus. Some caspases or their target(s) are likely translocated from the cytoplasm to the nucleus. Translocation of some caspases into the nucleus would be consistent with the observations that nuclear proteins such as lamins and poly(ADP)-ribose polymerase are cleaved by caspases (Martin and Green, 1995). It has recently been shown using a reconstituted system with naked nuclei and death lysates that the presence of ATP is necessary for chromatin condensation and nuclear fragmentation but not for DNA fragmentation (Kass et al, 1996). Note that apparent ATP-independence of DNA fragmentation does not necessarily indicate that cytosolic effectors for DNA fragmentation might gain access to the nuclear matrix in the absence of ATP because nuclear transport with naked nuclei does not require the ATPdependent mechanism any more.

Given that the Fas-initiated death signal is transferred via caspase-8 recruited into the Fas receptor complex to the caspase cascade that includes caspase-3 (reviewed by Nagata, 1997), the existence of an ATP-dependent step(s) upstream of the activation of caspase-3 might mean that the signal transduction pathway from Fas to the caspase cascade is regulated by protein phosphorylation.

\section{Conversion of apoptotic signals to necro- tic signals under ATP-depleting condition}

Treatment with calcium ionophore induces apoptosis under ATP-supplying conditions but necrotic cell death under ATPdepleting conditions (Eguchi et al, 1997), indicating that ATP levels are a determinant of how cell death is manifested, and apoptotic signals might be converted to necrotic signals in at least some cases. Note that although chemical hypoxia- and hypoxia-induced necrotic cell death require the activation of caspases, ATP depletion after the Fas-mediated activation of caspase-3(-like) proteases failed to convert efficiently Fasinitiated signals to necrotic signals, raising the possibilty that different caspases might be activated by the respective cell death stimuli. Alternatively, necrotic cell death fate might also depend on additional signals that are co-operated only by some cell death stimuli. Since activation of caspase- 3 is not observed in calcium ionophore-induced necrosis under ATP. deleting condition, some forms of necrosis might proceed independent of caspase activation simply through cellular collapse (Figure 2) although activation of another caspases might be involved. It should be noted that in the case of hypoxia- and chemical hypoxia-induced necrosis, the death signal flows through caspase activation because the cell death is suppressed by caspase inhibitors (Shimizu et al, $1996 \mathrm{~b}-\mathrm{e})$. Thus, necrosis might be classified into two categories, one that shares common steps with apoptosis and one that does not.

\section{Implications}

ATP-dependence of apoptosis but not necrosis might explain the frequent appearance of necrotic cells mixed with apoptotic cells in pathological areas in vivo, such as the center of solid tumors (reviewed by Ledda-Columbano and Columbano, 1991 and by Szende et al, 1991) and ischemic nervous tissues (reviewed by Chaniaut-Marlangue et al, 1996). In areas where blood flow is limited, intracellular ATP supplies are rapidly exhausted due to insufficient oxygen and rapid consumption of glucose, inhibiting apoptosis and inducing necrotic cell death. Thus, in vivo, intracellular ATP levels appear to be one of the factors that determine cell death fate by apoptosis or necrosis.

When glucose is provided in a medium, respiratory chain inhibitors, depending on cell lines or cell types, induce apoptosis or necrosis (Shimizu et al, 1996a). The distinction is due to the cell's dependence on respiration to maintain intracellular ATP levels. Cells depending more on mitochondria for ATP, die by necrosis because of energy crisis and cells with larger contribution of glycolysis die by apoptosis because of lowered intracellular ATP levels which are still sufficient for apoptosis.

As often noted, another factor affecting modes of cell death might be the concentrations of toxic reagents used; the same reagent induces apoptosis at lower concentrations but kills cells by necrosis at higher concentrations probably due to the rapid collapse of cellular integrity including plasma membrane disruption, a large calcium influx (extensively discussed by Nicotera, this issue) as well as intracellular ATP depletion. 
Cells that die pathologically but by apoptosis do not generate any warning to the host through inflammation and might be cleared by normal apoptotic mechanisms of engulfment. Small-scale pathological cell death might not merit a warning to the host or might be a sacrifice for having apoptotic mechanisms.

Since apoptosis is tightly regulated at genetic levels, optimism exists that diseases caused by enhanced apoptosis might be treated by inhibiting molecular processes with drugs or through some gene therapy. However, since at least some forms of necrosis are rescued by anti-apoptotic agents, the question of whether the cells of interest die by apoptosis or necrosis might be less important than knowledge about the mechanisms underlying the cell death.

\section{Acknowledgements}

The work in my laboratory was carried out primarily by Drs Yutaka Eguch and Shigeomi Shimizu. I thank Ms Marina Hoffman for editorial assistance.

\section{References}

Akao Y, Otsuki Y, Kataoka S, Ito $Y$ and Tsujimoto $Y$ (1994) Multiple subcellular localization of bcl-2: Detection in nuclear outer membrane, endoplasmic reticulum membrane and mitochondrial membranes. Cancer Res. 54: 24682471

Alison MR and Sarraf CE (1994) Liver cell death: patterns and mechanisms. Gut 35: $577-581$

Alnemri ES, Livingston DJ, Nicholson DW, Salvesen G, Thornberry NA, Wong WW and Yuan J (1996) Human ICE/CED-3 protease nomenclature. Cell 87: 171

Armstrong RC, Aja T, Xiang J, Gaur S, Krebs JF, Hoang K, Bai X, Korsmeyer SJ, Karanewsky DS, Fritz LC and Tomaselli KJ (1996) Fas-induced activation of the cell death-related protease CPP32 is inhibited by Bcl-2 and by ICE family protease inhibitors. J. Biol. Chem. 271: 16850-16855

Boulakia CA, Chen G, Ng FWH, Teodoro JG, Branton PE, Nicholson DW, Poirier GG and Shore GC (1996) Bcl-2 and adenovirus E1B $19 \mathrm{kDA}$ protein prevent E1Ainduced processing of CPP32 and cleavage of poly (ADP-ribose) polymerase. Oncogene 12: $529-535$

Charriaut-Marlangue C, Aggoun-Zouaoui D, Represa A and Ben-Ari Y (1996) Apoptotic features of selective neuronal death in ischemia, epilepsy and gp 120 toxicity. Trends Neurosci. 19: 109-114

Chinnaiyan AM, Orth K, O'Rouke K, Duan H, Poirier GG and Dixit VM (1996) Molecular ordering of the cell death pathway: $\mathrm{Bcl}-2$ and $\mathrm{Bcl}-\mathrm{xL}$ function upstream of the Ced-3-like apoptotic proteases. J. Biol. Chem. 271: 4573-4576

Chinnaiyan AM, O'Rourke K, Lane BR and Dixit VM (1997) Interaction of CED-4 with CED-3 and CED-9: A molecular framework for cell death. Science 275: 11221126

Clem RJ and Miller LK (1994) Induction and inhibition of apoptosis by insect viruses. In: Tomei LD and Cope FO (eds) Apoptosis Il: The molecular basis of apoptosis in diseases. pp 89-110, Cold Spring Harbor Laboratory Press

Cory S (1995) Regulation of lymphocyte survival by the bcl-2 gene family. Ann. Rev. Immunol. 13: 513-543

Enari M, Talanian RV, Wong WW and Nagata S (1996) Sequential activation of ICElike and CPP32-like proteases during Fas-mediated apoptosis. Nature 380: $723-726$

Eguchi Y, Shimizu S and Tsujimoto Y (1997) Intracellular ATP levels determine cell death fate by apoptosis or necrosis. Cancer Res. in press

Hawkins HK, Ericsson JLE, Biberfeld P and Trump BF (1972) Lysosome and phagosome stability in lethal cell injury. Morphologic tracer studies in cell injury due to inhibition of energy metabolism, immune cytolysis and photosensitization. Am. J. Pathol. 68: 255-258

Hay BA, Wassarman DA and Rubin GM (1995) Drosophila homologs of Baculovirus inhibitor of apoptosis proteins function to block cell death. Cell 83: 1253-1262
Hockenbery D, Nunez G, Milliman C, Schreber RD and Korsmeyer SJ (1990) Bcl-2 is an inner mitochondrial membrane protein that blocks programmed cell death. Nature 348: $334-336$

Jacobson MD, Burne JF, King MP, Miyashita T, Reed JC and Raff MC (1993) Bcl-2 blocks apoptosis in cells lacking mitochondrial DNA. Nature 361: 365-369

Kane DJ, Sarafian TA, Anton R, Hahn H, Gralla EB, Valentine JS, OrdT and Bredesen DE (1993) Bcl-2 inhibition of neural death: Decreased generation of reactive oxygen species. Science 262: $1274-1277$

Kane DJ, Ord T, Anton R and Bredesen DE (1995) Expression of bcl-2 inhibits necrotic neural cell death. J. Neurosci. Res. 40: 269-275

Kass GE, Ericksson JE, Weis M, Orrenius S and Chow SC (1996) Chromatin condensation during apoptosis requires ATP. Biochem. J. 318: 749-752

Kluck RM, Bossy-Wetzel E, Green DR and Newmeyer DD (1997) The release of cytochrome $\mathrm{c}$ from mitochondria: A primary site for $\mathrm{Bcl}-2$ regulation of apoptosis. Science 275: $1132-1136$

Kroemer G (1997) Mitochondrial implication in apoptosis. Towards an endosymbiont hypothesis of apoptosis evolution. Cell Death and Differ. 4: 443-456

Kumar S (1995) ICE-like proteases in apoptosis. TIBS 20: 198-202

Ledda-Columbano GM and Columbano A (1991) Apoptosis and hepatocarcinogenesis, In: Tomei LD and Cope FO (eds), Apoptosis: The molecular basis of cell death. pp 101-119. Cold Spring Harbor Laboratory Press

Leist M, Single B, Castoldi AF, Kenle S and Nicotera P (1997) Intracellular ATP concentration: a switch deciding between apoptosis and necrosis. J. Exp. Med. in press

Liu X, Kim CN, Yang J, Lemmerson R and Wang X (1996) Induction of apoptotic program in cell-free extracts: Requirement for dATP and cytochrome c. Cell 86: $147-157$

Martin SJ and Green DR (1995) Protease activation during apoptosis: death by a thousand cuts? Cell 82: 349-352

Monaghan P, Robertson D, Amos TAS, Dyer MJS, Mason DY and Greaves MF (1992) Ultrastructural localization of Bcl-2 protein. J. Histochem. Cytochem. 40: 18191825

Nagata S (1997) Apoptosis by death factor. Cell 88: 1-20

Nicotera P and Leist M (1997) Energy supply and the shape of death in neurons and lymphoid cells. Cell Death and Differ. 4: 435-442

Shimizu S, Eguchi Y, Kosaka H, Kamiike W, Matsuda H and Tsujimoto Y (1995) Prevention of hypoxia-induced cell death by Bcl-2 and Bcl-xL. Nature 374:811813

Shimizu S, Eguchi Y, Kamiike W, Itoh Y, Hasegawa J-I, Yamabe K, Ohtsuki Y, Matsuda $H$ and Tsujimoto $Y$ (1996a) Induction of apoptosis as well as necrosis by hypoxia and predominant prevention of apoptosis by bcl-2 and bcl-xL. Cancer Res. 56: 2161-2166

Shimizu S, Eguchi Y, Kamiike W, Waguri S, Uchiyama Y, Matsuda Hand Tsujimoto Y (1996b) Retardation of chemical hypoxia-induced necrotic cell death by Bcl-2 and ICE inhibitors: Possible common steps in apoptosis and necrosis. Oncogene 12: $2045-2050$

Shimizu S, Eguchi Y, Kamiike W, Matsuda H and Tsujimoto Y (1996c) Bcl-2 expression prevents activation of the ICE protease cascade. Oncogene 12 2251-2257

Shimizu S, Eguchi Y, Kamiike W, Waguri S, Uchiyama Y, Matsuda Hand Tsujimoto Y (1996d) Bcl-2 blocks loss of mitochondrial membrane potential while ICE inhibitors act at a different step during inhibition of death induced by respiratory chain inhibitors. Oncogene 13: 21-29

Shimizu S, Eguchi Y, Kamiike W, Akao Y, Kosaka H, Hasegawa J-i, Matsuda H and Tsujimoto Y (1996e) Involvement of ICE family proteases in apoptosis induced by reoxygenation of hypoxic hepatocytes. Am. J. Physiol. 271: G949-G958

Steller H (1995) Mechanisms and genes of cell suicide. Science 267: 1445-1449

Strasser A, Harris AW and Cory S (1991) bcl-2 transgene inhibits T cell death and perturb thymic self-censorship. Cell 67: 889-899

Susin SA, Zamzami N, Castedo M, Hirsch T, Marchetti P, Macho A, Daugas E, Geuskern M and Kroemer G (1996) Bcl-2 inhibits the mitochondrial release of an apoptogenic protease. J. Exp. Med. 184: 1-11

Szende B, Schally AV, Comaru-Schally AM, Redding TW, Srkalovic G, Groot K, Lapi K, Timar J, Neill J and Mulchahey J (1991) Cellular and molecular aspects of apoptosis in experimental tumors of animals treated with analog of $\mathrm{LHRH}$ and somatostatin. In: Tomei LD and Cope FO (eds) Apoptosis: The molecularbasis of cell death. pp 139-155. Cold Spring Harbor Laboratory Press

Thompson CB (1995) Apoptosis in the pathogenesis and treatment of diseases. Science 267: $1456-1462$ 
Wyllie AH, Kerr JFR and Currie AR (1980) Cell death: the significance of apoptosis. Int. Rev. Cytology 68: 251-306

Yasuhara N, Eguchi Y, Tachibana T, Imamoto N, Yoneda $Y$ and Tsujimoto $Y$ (1997) Essential role of active nuclear transport in apoptosis. Genes to Cells, 2: $55-64$

Yang J, Liu X, Bhalla K, Kim CN, Ibrado AM, Cai J, Peng T-I, Jones DP and Wang X (1997) Prevention of apoptosis by Bcl-2: Release of cytochrome c from mitochondria blocked. Science 275: 1129-1132
Zamzami N, Marchetti P, Castedo M, Decaudin D, Macho A, Hirsh T, Susin SA, Petit PX, Mignotte B and Kroemer G (1996a) Sequential reduction of mitochondrial transmembrane potential and generation of reactive oxygen species in early programmed cell death. J. Exp. Med. 182: 367-377

Zamzami N, Marchetti P, Castedo M, Zanin C, Vayssiere J-L, Petit PX and Kroemer G (1995b) Reduction in mitochondrial potential constitutes an early irreversible step of programmed lymphocyte death in vivo. J. Exp. Med. 181: 1661 - 1672 